also to lower soy consumption..$^{13}$ Therefore, the lack of adjustment for socio-economic status is an important potential limitation, as the authors themselves recognise. With regard to other potential confounders, it would have been interesting to account for hormonal factors, since oestrogen-related factors are linked to both soy intake and asthma control. ${ }^{6,14}$ Likewise, it is possible that soy intake varies with the intake of other nutrients and foods, and that these other dietary factors may contribute to the observed association.

Although the role of diet on the aetiology of adult-onset asthma appears limited ${ }^{2}$ its role as a disease modifier continues to have promise. Even if we are sceptical about the recommendation to consume the "right" amount of soy to improve asthma control, ${ }^{5}$ we agree with the authors about the value of further research. Randomised controlled trials are needed to truly understand how dietary interventions, including weight loss, ${ }^{15}$ may promote asthma control.

Conflicts of interest The authors declare that they have no conflicts of interest in relation to this article.

Commissioned article; not externally peer-reviewed; accepted 30th October 2012; online 8th November 2012

() 2012 Primary Care Respiratory Society UK. All rights reserved

http://dx.doi.org/10.4104/pcri.2012.00095

Prim Care Respir J 2012; 21(4): 367-368

\section{References}

1. Moorman JE, Zahran H, Truman BI, Molla MT; Centers for Disease Control and Prevention (CDC). Current asthma prevalence - United States, 2006-2008. MMWR Surveill Summ 2011;60 Suppl:84-6.

2. Varraso R. Nutrition and asthma. Curr Allergy Asthma Rep 2012;12:201-10. http://dx.doi.org/10.1007/s11882-012-0253-8

3. Wenzel SE. Asthma phenotypes: the evolution from clinical to molecular approaches. Nat Med 2012;18:716-25. http://dx.doi.org/10.1038/nm.2678

4. Barros R, Moreira A, Fonseca J, et al. Adherence to the Mediterranean diet and fresh fruit intake are associated with improved asthma control. Allergy
2008:63:917-23. http://dx.doi.org/10.1111/j.1398-9995.2008.01665.x

5. Bime C, Wei CY, Holbrook J, Smith U, Wise RA. Association of dietary soy genistein intake with lung function and asthma control: a post-hoc analysis of patients enrolled in a prospective multicentre clinical trial. Prim Care Respir J 2012;21(4):398-404. http://dx.doi.org/10.4104/pcrj.2012.00073

6. Messina M. A brief historical overview of the past two decades of soy and isoflavone research. J Nutr 2010;140:1350S-4S. http://dx.doi.org/10.3945/jn.109.118315

7. Sacks FM, Lichtenstein A, Van Horn L, Harris W, Kris-Etherton P, Winston M. Soy protein, isoflavones, and cardiovascular health. An American Heart Association science advisory for professionals from the nutrition committee. Circulation 2006;113:1034-44. http://dx.doi.org/10.1161/CIRCULATIONAHA.106.171052

8. Woods RK, Walters EH, Raven JM, et al. Food and nutrient intakes and asthma risk in young adults. Am J Clin Nutr 2003;78:414-21.

9. Miyake Y, Sasaki S, Ohya Y, et al. Soy, isoflavones, and prevalence of allergic rhinitis in Japanese women: the Osaka Maternal and Child Health Study. J Allergy Clin Immuno/ 2005;115:1176-83. http://dx.doi.org/10.1016/j.jaci.2005.02.016

10. Butler LM, Koh WP, Lee HP, Yu MC, London SJ. Dietary fiber and reduced cough with phlegm: a cohort study in Singapore. Am J Respir Crit Care Med 2004;170:279-87. http://dx.doi.org/10.1164/rccm.200306-7890C

11. Smith $\amalg$, Holbrook JT, Wise R, et al. American Lung Association Asthma Clinical Research Centers. Dietary intake of soy genistein is associated with lung function in patients with asthma. J Asthma 2004;41:833-43.

http://dx.doi.org/10.1081/JAS-200038447

12. Boudreaux ED, Emond SD, Clark S, Camargo CA Jr. Acute asthma among adults presenting to the emergency department: the role of race/ethnicity and socioeconomic status. Chest 2003;124:803-12.

http://dx.doi.org/10.1378/chest.124.3.803

13. Turrell G, Kavanagh AM. Socio-economic pathways to diet: modelling the association between socio-economic position and food purchasing behaviour. Public Health Nutr 2006;9:375-83. http://dx.doi.org/10.1079/PHN2006850

14. Varraso R, Siroux V, Maccario J, Pin I, Kauffmann F. Epidemiological Study on the Genetics and Environment of Asthma. Asthma severity is associated with body mass index and early menarche in women. Am J Respir Crit Care Med 2005;171:334-9. http://dx.doi.org/10.1164/rccm.200405-6740C

15. Ma J, Strub P, Camargo CA Jr, et al. The Breathe Easier through Weight Loss Lifestyle (BE WELL) Intervention: a randomized controlled trial. BMC Pulm Med 2010;10:16. http://dx.doi.org/10.1186/1471-2466-10-16

\title{
Predicting the risk of an asthma attack: the way ahead?
}

\section{See linked article by Hyland et al. on pg 405}

\section{*Chris Griffiths', Noreen Clark ${ }^{2}$}

1 Professor of Primary Care, Centre for Primary Care and Public Health, Blizard Institute, Barts and the London School of Medicine and Dentistry, Queen Mary University of London, London, UK

2 Myron E. Wegman Distinguished University Professor, Director, Center for Managing Chronic Disease, University of Michigan, Ann Arbor, Michigan, USA

*Correspondence: Professor Chris Griffiths, Centre for Primary Care and Public Health, Blizard Institute, Barts and the London School of Medicine and Dentistry, Queen Mary University of London, Yvonne Carter Building, 58 Turner St, London, E1 2AB, UK Tel: +44 (0)207 8822509 Fax: +44 (0)207 8822552

E-mail: c.j.griffiths@qmul.ac.uk
Targeting care at those at highest risk of an asthma attack is an attractive concept. Asthma attacks are at best unpleasant, at worst catastrophic and even fatal. Asthma attacks drive health care costs (largely via hospitalisation) and costs to society (via loss of work), ${ }^{1}$ and reducing hospitalisation is the key to reducing the overall costs of asthma care. ${ }^{2}$ The concept of good asthma control fundamentally includes the notion of an individual's likelihood of experiencing an attack. ${ }^{3}$

Risk prediction is growing in importance - both to the individual and at the public health level. Risk scores already exist to predict, for example, the risk of future cardiovascular events, ${ }^{4}$ development of diabetes, ${ }^{5}$ and lung cancer. ${ }^{6}$ UK general practices now routinely use risk-stratification tools to identify - and then target with preventive care - patients at highest risk of hospitalisation.

In this issue of the PCRJ, Hyland and colleagues ${ }^{7}$ report an observational study testing the intriguing hypothesis that a person's risk of a future asthma exacerbation is related to their past attendance 
in primary care for problems other than asthma. They assessed a range of variables in 166 people with asthma at an asthma clinic in a single UK general practice, and then gathered data on attendance for the following five years from their medical records. Data included medication adherence (both self-reported and assessed from prescriptions), severity (as medication step), and demographic factors. They found that non-asthma visits to primary care were a stronger predictor of future asthma exacerbations than either asthma severity or medication adherence. This relationship held not just for attendances for ENT problems (which might suggest respiratory dysfunction) but also for gastrointestinal and psychological problems. The authors propose that higher numbers of non-asthma visits are a marker of a 'dysregulated' or 'dysfunctional' patient. They speculate as to whether the relationship reflects a behavioural or biomedical, perhaps inflammation-mediated, mechanism. A third potential explanation is that higher numbers of non-asthma visits are a marker of a dysfunctional clinical system that does not adequately cope with multimorbidity ${ }^{8}$ - i.e. the coordination of care and consideration of multiple problems in making treatment decisions may be lacking. Data on multimorbidity in the study population would allow this idea to be explored.

Hyland and colleagues acknowledge the limitations of a study set in a single UK general practice. ${ }^{7}$ Clearly it would be worthwhile testing these relationships in other larger, and more demographically diverse, datasets. Although not part of their hypothesis, it would have been interesting to report the relationship between prior and future asthma exacerbations. Nonetheless, the authors are confident they have identified a potentially useful predictor of risk of future emergency consultation for asthma. They make the point that a narrow focus on adherence or severity may not fully capture this risk.

A number of approaches have been taken to predicting risk of future asthma exacerbations. ${ }^{9}$ Some have focused on monitoring fluctuations in peak expiratory flow rate, ${ }^{10}$ symptoms and questionnaire scores, ${ }^{11}$ or biomarkers of inflammation; others have focused on the frequency of past consultations.? Some have tried to predict exacerbations themselves, ${ }^{10}$ others the risk of an attendance with an asthma exacerbation.?

Predicting the risk of attendance with an asthma exacerbation is likely to be more problematic than predicting the risk of harder disease outcomes like lung cancer, diabetes and myocardial infarction. Firstly, asthma is recognised as a condition with multiple, potentially distinct phenotypes. ${ }^{9}$ Each may vary in its likelihood of deterioration. Second, some attacks, even severe ones, do not lead to a consultation with a health care professional. As the American sociologist Irving Zola pointed out, help-seeking is a social process. ${ }^{12}$ Whether or not a person ultimately attends health care with an asthma attack will depend on the context and their interpretation of their symptoms, ${ }^{12}$ their abilities to self-care, ${ }^{13}$ and their past experience of consultations, ${ }^{14}$ as well as practical, economic and logistical aspects of accessing care. ${ }^{14}$ These are factors that are difficult to quantify, but may go some way to explaining the very large variations in unscheduled care for asthma seen across different ethnic groups. ${ }^{15}$

Just as with cardiovascular disease, ultimately the most useful approach to risk prediction for asthma is likely to come from analyses of very large primary care datasets. ${ }^{4}$ Predictor variables will need to capture a diversity of demographic factors including social deprivation and ethnicity, biological measures of disease such as lung function, aspects of management including medication and adherence, lifestyle - notably smoking status, and consultation behaviour including frequencies of attendance for asthma and non-asthma related care. Validation of a model's predictive abilities in a subsequent dataset will strengthen its credibility. Finally, the test of its usefulness should include comparing the impact of targeted care using the risk prediction tool with usual asthma care, probably using a design incorporating cluster randomisation of primary care practices. The study would need to be large enough to assess benefits for those targeted as well as potential poor outcomes for those whose care might be less effective because they are in a low risk group.

This highlights an essential aspect of an important debate: the attraction of risk prediction is that it enables targeting of those at highest risk of an exacerbation. However, it is clear from studies of asthma deaths ${ }^{16,17}$ that severe and fatal attacks can appear out of the blue, affecting patients whose risk scores might place them in a group which would mean they would be neglected if care was driven entirely by risk prediction. Interestingly, the approach taken in the Finnish Asthma Programme, which successfully reduced hospitalisation and health care costs, was largely untargeted, emphasising better care and anti-inflammatory treatment for all asthma patients. ${ }^{2}$

In summary, two challenges remain: first, we need to produce better risk prediction tools for people with asthma; second, we need to prove they lead to better care.

Conflicts of interest The authors declare that they have no conflicts of interest in relation to this article. CG is an Assistant Editor of the PCRJ, but was not involved in the editorial review of, nor the decision to publish, this article.

Commissioned article; not externally peer-reviewed; accepted 7th November 2012; online 19th November 2012

(C) 2012 Primary Care Respiratory Society UK. All rights reserved

http://dx.doi.org/10.4104/pcrj.2012.00101

Prim Care Respir J 2012; 21(4): 368-370

\section{References}

1. Bahadori K, Doyle-Waters MM, Marra C, et al. Economic burden of asthma: a systematic review. BMC pulmonary medicine 2009;9:24. Epub 2009/05/21.

2. Haahtela $T$, Tuomisto $L E$, Pietinalho $A$, et al. A 10 year asthma programme in Finland: major change for the better. Thorax 2006;61(8):663-70.

http://dx.doi.org/10.1136/thx.2005.055699

3. Reddel HK, Taylor DR, Bateman ED, et al. An Official American Thoracic Society/European Respiratory Society Statement: Asthma Control and Exacerbations. Am J Respir Crit Care Med 2009;180(1):59-99. http://dx.doi.org/10.1164/rccm.200801-060ST

4. Hippisley-Cox J, Coupland C, Vinogradova Y, et al. Predicting cardiovascular risk in England and Wales: prospective derivation and validation of QRISK2. BMJ 2008;336(7659):1475-82. http://dx.doi.org/10.1136/bmj.39609.449676.25

5. Hippisley-Cox J, Coupland C, Robson J, Sheikh A, Brindle P. Predicting risk of type 2 diabetes in England and Wales: prospective derivation and validation of QDScore. BMJ 2009;338.

6. Cassidy A, Myles JP, van Tongeren $\mathrm{M}$, et al. The LLP risk model: an individual risk prediction model for lung cancer. $\mathrm{Br} J$ Cancer 2007;98(2):270-6. http://dx.doi.org/10.1038/sj.bjc.6604158

7. Hyland ME, Whalley B, Halpin DMG, et al. Frequency of non-asthma GP visits predicts asthma exacerbations: an observational study in general practice. Prim 
Care Respir J 2012;21(4):405-11. http://dx.doi.org/10.4104/ pcrj.2012.00061

8. U.S. Department of Health and Human Services. U.S. Department of Health and Human Services (HHS) Inventory of Programs, Activities and Initiatives Focused on Improving the Health of Individuals with Multiple Chronic Conditions (MCC). Compiled by the HHS Interagency Workgroup on Multiple Chronic Conditions under the direction of Anand Parekh, MD, MPH, Deputy Assistant Secretary for Health (Science and Medicine), Office of the Assistant Secretary for Health. September 2011].

9. Frey U, Suki B. Complexity of chronic asthma and chronic obstructive pulmonary disease: implications for risk assessment, and disease progression and control. Lancet 2008:372(9643):1088-99. http://dx.doi.org/10.1016/S0140-6736(08)61450-6

10. Thamrin $C$, Zindel J, Nydegger $R$, et al. Predicting future risk of asthma exacerbations using individual conditional probabilities. J Allergy and Clin Immunol 2011;127(6):1494-502.e3

11. Bateman ED, Reddel HK, Eriksson G, et al. Overall asthma control: The relationship between current control and future risk. I Allergy and Clin Immunol 2010; 125(3):600-8.e6.
12. Zola IK. Pathways to the doctor-From person to patient. Soc Sci Med 1973; 7(9):677-89. http://dx.doi.org/10.1016/0037-7856(73)90002-4

13. Hinder $S$, Greenhalgh T. "This does my head in". Ethnographic study of selfmanagement by people with diabetes. BMC Health Services Research 2012;12(1):83. http://dx.doi.org/10.1186/1472-6963-12-83

14. Griffiths C, Kaur G, Gantley M, et al. Influences on hospital admission for asthma in south Asian and white adults: qualitative interview study. BMJ 2001; 323(7319):962-6. Epub 2001/10/27.

15. Netuveli G, Hurwitz B, Levy M, et al. Ethnic variations in UK asthma frequency, morbidity, and health-service use: a systematic review and meta-analysis. Lancet 2005;365(9456):312-17.

16. Harrison B, Stephenson P, Mohan G, Nasser S. An ongoing Confidential Enquiry into asthma deaths in the Eastern Region of the UK, 2001-2003. Prim Care Respir J 2005;14(6):303-13. http://dx.doi.org/10.1016/j.pcrj.2005.08.004

17. Anagnostou $K$, Harrison B, lles R, Nasser S. Risk factors for childhood deaths from the UK Eastern Region Confidential Enquiry 2001-2006. Prim Care Respir J 2012; 21(1):71-7. http://dx.doi.org/10.4104/pcrj.2011.00097

Available online at http://www.thepcrj.org 